Original Research

\title{
Men's Bones Matter Too, a Cross Sectional Study Examining Bone Health among Men with Intellectual Disability in Ireland.
}

Éilish A Burke ${ }^{1,}{ }^{*}$, Rachael Carroll ${ }^{1}$, Angela W. Ding ${ }^{2}$, Melisa Yaman ${ }^{2}$, J. Bernard Walsh ${ }^{3}$, Philip McCallion ${ }^{4}$, Mary McCarron ${ }^{5}$

1. Trinity Centre for Ageing and Intellectual Disability, School of Nursing and Midwifery, Trinity College Dublin, Ireland; E-Mails: eburke7@tcd.ie; CARROLR5@tcd.ie

2. School of Nursing, University of Pennsylvania, 418 Curie Blvd, Philadelphia PA 19104, US; E-Mails: ading125@nursing.upenn.edu; melisay@nursing.upenn.edu

3. Medical Gerontology, School of Medicine, Trinity College Dublin; E-Mail: Jbwalsh@tcd.ie

4. College of Public Health, Temple University, Bell Building, 1101 W. Montgomery Ave, Philadelphia, PA 19122; E-Mail: Philip.mccallion@temple.edu

5. Trinity Centre for Ageing and Intellectual Disability, School of Nursing and Midwifery, Trinity College Dublin; E-Mail: mccarrm@tcd.ie

* Correspondence: Éilish A Burke; E-Mail: eburke7@tcd.ie

Academic Editor: Ray Marks

Special Issue: $\underline{\text { Research on Bone Diseases in Older Adults }}$

OBM Geriatrics

2021, volume 5 , issue 4

doi:10.21926/obm.geriatr.2104182
Received: June 23, 2021

Accepted: October 21, 2021

Published: November 08, 2021

\begin{abstract}
Globally between $30-40 \%$ of all osteoporotic fractures occur among men, with a quarter of all hip fractures, the most serious complication of osteoporosis, occurring in men. Among men of 50 years of age or older, osteoporotic fracture risk reaches an alarming $20 \%$. What is of great concern is that associated mortality is greater among men when compared with women. For hip fractures specifically, mortality for men is two to three times that in women which may be attributed to the fact that osteoporosis is often considered a "women's disease". Of great concern is that there is a paucity of bone health investigation among men with intellectual disability. In the Intellectual Disability Supplement to The Irish Longitudinal Study
\end{abstract}

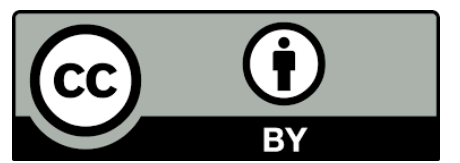

(C) 2021 by the author. This is an open access article distributed under the conditions of the Creative Commons by Attribution License, which permits unrestricted use, distribution, and reproduction in any medium or format, provided the original work is correctly cited. 
on Ageing, objective bone status of 244 men was measured using a quantitative ultrasound. Participant's also self-reported doctor's diagnosis of health conditions including osteoporosis, medication and fracture history with the assistance of key workers/family. Ethical approval for the study was obtained from the Faculty of Health Sciences Trinity College and all participating service providers. Overall, $70.9 \%$ of men presented with poor bone health, with $57.8 \%$ taking at least one medication that contributed to osteoporosis/osteopenia. Men had a high prevalence of fracture $(21.7 \%)$ despite this less than $18 \%$ had attended bone health screening. In light of these findings, it is time for the spotlight to focus on men's bone health and for healthcare professionals to realise how 'at risk' of osteoporosis are men with intellectual disability. Projections place men on a trajectory of continuous increased risk of fracture in comparison to women.

\section{Keywords}

Osteoporosis; men's bone health; intellectual disability

\section{Introduction}

People with Intellectual Disabilities make up approximately $2 \%$ of the population and are reported to experience poorer health status than the general population [1, 2]. People with ID have an average life expectancy 19 years shorter than those with no intellectual disabilities [3]. Very often, serious health conditions go unrecognized or undiagnosed because of health disparities, barriers to health care, inequality of services, as well as other factors that affect this population of people [1, $2,4]$. One such condition is osteoporosis, an insidious skeletal disease defined by the presence of low bone density and the deterioration of bone tissue [5]. People with intellectual disability, especially those with Down syndrome (DS), prone to premature ageing and who are living longer than before, are particularly at a higher risk for osteoporosis and its secondary health conditions (e.g. fractures) [6, 7] however there are other syndromes that can contribute to poor bone health such as Prader-Willi syndrome, Angelman syndrome and Fragile $X$ syndrome. Osteoporosis is often diagnosed by measuring bone mineral density (BMD), usually through dual energy X-ray absorptiometry (DXA) [5]. However, relying on BMD alone is not sufficient for diagnosing osteoporosis, risk factors must be taken into consideration [8]. The risk of developing osteoporosis includes both non-modifiable and modifiable factors. Notable non-modifiable risk factors include increased age, female gender, a familial history of osteoporosis, antiepileptic drug use, and some gastrointestinal diseases. Along with this is the issue that some individuals with ID may not reach peak bone mass for example those with DS [6]. Notable modifiable risk factors include physical inactivity, taking certain medications for mental illnesses, poor dietary habits, obesity, constipation, vitamin $D$ and estrogen deficiency $[9,10]$. Greater frequency of these risk factors leads to bone deterioration which ultimately leads to heightened bone fragility and in turn is shown to lead to a higher risk of fractures morbidity and mortality, which can severely limit and affect quality of life [8, 11, 12].

Recently, research has shown that people with intellectual disability and DS have been reported to have lower BMD than people without either condition, specifically within the lower lumbar and 
femoral neck regions, and upper and lower limbs [6, 13]. In recent large-scale studies, over 35\%-40\% of older participants with intellectual disability had objective evidence of osteoporosis [14, 15]. Similar findings by Frighi and colleagues confirm high prevalence of poor bone health among this cohort [16]. Even with this markedly higher than normal rate, it's possible that many cases of osteoporosis in people with intellectual disability continue to go undiagnosed. For people with intellectual disability there are numerous biological, physiological, and behavioural factors that may contribute to overall health imbalance and increased risk of poor bone health. People with intellectual disability are known to get much less physical exercise than the recommended daily amount [17]. They often do not have sufficient calcium or vitamin D sources in their diets [18]. Higher levels of epilepsy and mental illnesses such as depression and subsequent antiepileptic and psychotropic medicines have a negative impact on bone health [19-21] and specific syndromes such as DS or Prader-Willi syndrome contribute to overall poor skeletal development which may be as a result of a combination of factors with would include hypogonadism, thyroid disease and immature bone development [22]. It has been recorded that approximately $20-45 \%$ of people with intellectual disability are receiving psychotropic medication [23]. In addition, recent research has shown that obesity and bone mass have an inverse relationship and that osteoporosis is often an underlying indication of gastrointestinal diseases (GIT) and vice versa [24, 25]. People with intellectual disability are more likely to develop obesity and GIT disorders than the general population [24-28].

Typical of healthcare settings there is often a gender focus for many health conditions, and with osteoporosis particularly men have not considered the condition nor have healthcare professionals focused on the condition to a great deal among men. Poor bone health is not discriminatory, and men are just as likely to present with the condition as women albeit later in life [29]. Therefore, as a result, the research on men's experiences of osteoporosis requires greater attention. Recent epidemiological and observational studies have shown that osteoporosis in men is an increasingly important clinical issue [30]. It is known that the lifetime risk of osteoporosis-related fracture in men has been estimated greater than their risk of developing prostate cancer and the estimated risk of hip fracture is rising exponentially [31]. For men, one-year mortality rates are higher following a hip fracture and compared to women, they are two to three times more likely to die post hip fracture [32]. Explanations for this lack of focus on men and osteoporosis are mainly that osteoporosis is widely considered a woman's disease. Studies show that even when diagnosed, men do not treat the diagnosis as significant because they perceive it as a woman's disease. A common response to diagnoses is "You know grandmothers have it and live through it" ([32], page 3). Men may feel constrained by gender stereotypes, feeling confined to a less masculine persona upon hearing their diagnosis [33]. Men may continue to endure through their pain and exert themselves through difficult tasks to justify their manliness. The inability for many men to treat their diagnosis as serious is the result of the assertion that osteoporosis is synonymous with older women [34]. This creates a gap between women's and men's attitude toward their health and must be more closely examined. However, the situation is not helped with much of the advertising, health campaigns and health promotions predominantly featuring women. It is no wonder then that men consider osteoporosis a female condition.

For men with intellectual disability there is an even less focus on their bone health status despite the high levels of risk previously mentioned and it is safe to say that perhaps their attitude would be similar to that of men without intellectual disability however this is not known for certain [35]. A number of reasons why men with intellectual disability are frequently overlooked may be due to 
the commonly missed GP health checks and lack of reasonable accommodations during health assessment, or simply bone health is not discussed during their health check [36]. People with intellectual disability are among a group of individuals that often miss out on their health evaluations as a result of barriers such as inaccessibility, lack of knowledge of local services and lack of support [37]. During osteoporosis evaluations the experience may pose difficulties due to the lack of reasonable adjustments and challenges with equipment, or individuals may simply be scared. People with ID have had complications in the past getting tested for osteoporosis because of the nature of the DXA test that may seem frightening or challenging for this population [38-40]. In frequent patient-physician interactions, the diagnosis itself proves to be more challenging because those with ID are often unable to express their symptoms or frightened by the DXA assessment [41]. Recent research has shown that the use of the GE Lunar Achilles quantitative Ultrasound (QUS) has the potential to be a much better alternative to the DXA for people with IDs, allowing for the undiagnosed and untested population to be more adequately monitored [6]. Nonetheless, after being diagnosed, some individuals have difficulty following through on their treatment plans and may find it challenging to adhere to physical therapy regimes, medications such as bisphosphonates or understanding the importance of the treatment due to lack of reasonable adjustments [37-40]. As mentioned above, osteoporosis is not a topic associated with men with intellectual disability, further exacerbating the demand for more attention.

Considering the paucity of research among men with intellectual disability and yet the potential for high rates of hidden osteoporosis which can ultimately lead to bone fragility and fracture, it is prudent to place the spotlight on this condition among men with intellectual disability. Therefore, the aim of this study is to explore the prevalence of osteoporosis among men with intellectual disability and the risks associated with poor bone health among this cohort.

\section{Materials and Methods}

The data for this paper was extracted from the Intellectual Disability Supplement to the Irish Longitudinal Study on Ageing (IDS-TILDA) which is a national longitudinal study exploring the health and wellbeing of individuals with intellectual disability in Ireland. Data is collected every three years and the data for this paper was from the second wave of the study in 2014 which included objective measures of bone health $[42,43]$.

\subsection{Study Design}

For inclusion in the study all participants must have been registered with the National Intellectual Disability Database, which is a service planning tool whereby individuals are registered to ensure receipt of services which enabled the random sample selection resulting in a representative sample of individuals over the age of 40 years [44]. The inclusion criteria comprised those over the age of 40 years at onset of IDS-TILDA [2008], this lower age was chosen because of noted premature ageing among those with intellectual disability. All levels of intellectual disability were included from mild, moderate to severe/profound. These were identified on initial interviews, are diagnosed using intelligent quotients and are for descriptive purposes only. Individuals were also invited to identify their living setting, and these were categorised into independent or living with family, living in a community group home or living in a residential setting which implies 10 or more residents. This paper is examining men only who engaged in the objective measurement for bone health $(\mathrm{N}=244)$ 
as a subsample of the total IDS-TILDA sample for Wave $2(\mathrm{~N}=708)$, see figure 1 for sample flow chart.

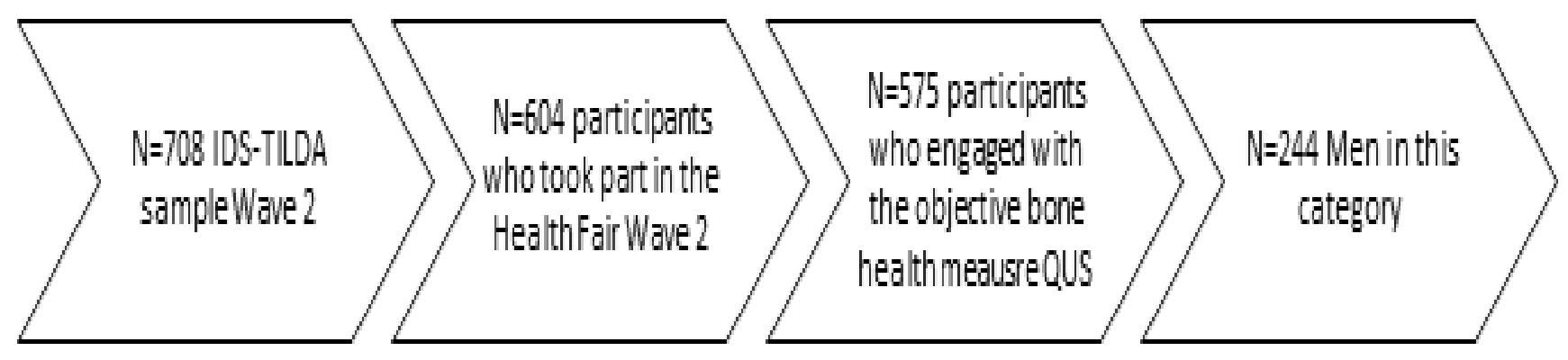

Figure 1 Sample flow chart.

\subsection{Data Collection}

IDS-TILDA collects data every 3 years, the approach includes a pre-interview questionnaire (PIQ), a face-to-face interview (CAPI) and in Wave 2 objective health measures. The PIQ includes questions on doctor's diagnosed conditions, which is a paper-based questionnaire that is posted to participants at minimum one week before their face-to-face interview. This is to allow sufficient time for participants to confirm with their doctor and medical files their medical history. The PIQ is then rechecked by the field researcher on the day of the interview. The interview is conducted at a time and place convenient to the participant, three styles of interview are offered, independent, supported and proxy only. The proxy must know and work with the participants for a minimum of 6 months. The CAPI collects data on a number of domains such as social, community engagement, physical activity, education, cognitive and mental health. Prior to the interview commencing the participant provides or were supported to provide informed consent, easy read material is provided to support this, as the interview progresses the field research will reaffirm consent as they move between domains. For full description of consent procedures see McCarron et al., Burke et al., and Burke et al. [43-45].

\subsubsection{Objective Health Measures}

A suite of 8 health measures were included in the second wave of data collection, these included height, weight, waist \& hip circumference, blood pressure, grip measurement, timed up \& go, and quantitative heel ultrasound (QUS), see Burke and colleagues for full explanation of the inclusion of objective measures [46]. Suffice to say dual energy X-ray absorptiometry (DXA) is recommended to evaluate bone density, however the QUS (GE Lunar Achilles) was a feasible measurement to determine bone quality and bone mass in this study. It was portable and acceptable for over $80 \%$ of the participants in the study. QUS parameters correlate with DXA, measure broadband ultrasound attenuation, speed of sound which calculates the stiffness index, associated with bone density obtained from conventional DXA methods [47]. The device calculates three parameters, broadband 
ultrasonic attenuation (BUA in dB/MHz), Speed of Sound (SOS in M/s) and Stiffness Index (SI, \%) which it then converts into those at high risk of fracture (osteoporosis), those at moderate risk (osteopenia) and those at low risk (normal). These parameters are expressed as QUS t-scores by the device. These parameters have been translated into risk estimate thresholds for clinical application [46]. In an effort to minimize the inappropriate use of QUS, Hans and colleagues use $90 \%$ sensitivity to define low fracture and osteoporotic risk and a specificity of $80 \%$ to define persons as being at high risk of fracture or of being osteoporotic. They combined their fracture model with their hip DXA osteoporotic model and found t-score parameters of -1.2 and -2.5 for the QUS Achilles stiffness index to determine those; a low risk (normal) above -1.2; moderate risk (-1.2 to -2.49; osteopenia); and $\geq-2.5$ at high-risk osteoporosis. These parameters have been utilised in this study.

In addition, the International Society of Clinical Densitometry official position is that the use of QUS is justified in the absence of DXA, use only validated devices (GE Lunar Achilles) and scan only at recommended sites, i.e. the os calcis (heel) [48]. The measures from the QUS are expressed in Tscores, Hans and colleagues combined a fracture model with their hip DXA osteoporotic model and found t-score parameters of -1.2 and -2.5 for the QUS Achilles stiffness index to determine those; a low risk (normal) above -1.2; moderate risk (-1.2 to -2.49 ; osteopenia); and >-2.5 at high risk osteoporosis $[48,49]$. These parameters have been utilised in this study.

Bone is living tissue that requires stimulation to promote regeneration and turnover; however, functional impairment can contribute to poorer bone health because of an increased functional dependence of the individual [50]. The Barthel Index is an instrument to measure performance in activities of living and functional independence. The Barthel's index includes 10 activities of living which include feeding, personal toileting, bathing, dressing and undressing, getting on and off a toilet, controlling bladder, controlling bowel, moving from wheelchair to bed and returning, walking on level surface (or propelling a wheelchair if unable to walk) and ascending and descending stairs [50]. Each variable is scored 0-2 or 0-3 with a total possible score range of 0-20.

Physical activity levels were determined using the International Physical Activity Questionnaire (IPAQ). Participants reported their frequency and duration of activity and these were categorised into low, moderate and high. The moderate level indicates meeting physical activity guidelines of 30 minutes of moderate intensity activity 5 days a week, 20 minutes of vigorous activity 3 days a week, or a combination indicates high levels of physical activity [51].

Hand grip strength is a simple measurement to identify overall muscular strength and is used as a clinical marker for sarcopenia. The European Working Group on Sarcopenia in Older People (EWGSOP) recommends using cut-offs for hand grip strength at two standard deviations below the mean reference value defined as $<30 \mathrm{kgs}$ in men $[52,53]$. This is the value that was applied in this study.

\subsection{Mapping Clinical Risk Factors}

Following a scoping literature review, examining the guidelines from the World Health Organisation and the International Osteoporosis Foundation clinical risk factors were identified and mapped to comparable data from the IDS-TILDA study. These were then categorised into modifiable and non-modifiable risk factors. 
Table 1 Mapping clinical risk factors.

\section{Known risk factors (Scoping literature review, Comparable data from the IDS-TILDA study WHO and IOF) [54-56]}

\section{Modifiable Factors}

Sedentary Behaviour

Levels of physical activity, mobility walking 100 yards-Difficulty/No difficulty, grip strength $>30 \mathrm{kgs}$

GIT conditions

Proton Pump Inhibitors

Smoking, alcohol consumption

\section{Non Modifiable Factors}

History of fracture/ parents history of fracture

Chronic health conditions

Anticonvulsant medication

Corticosteroid medication

Aetiology of intellectual disability
Gastric reflux, stomach ulcers, chronic constipation

Medication use-PPI

Smoking and alcohol intake*

History of fracture/ parents history of fracture[included as is strong indicator however $f=<5 \%$ ]

Arthritis, cerebral palsy, cancer, diabetes, thyroid disease, muscular dystrophy*, Scoliosis*, Coeliac disease*,

Epilepsy, AED use

Corticosteroid medication*

Down syndrome $\mathrm{Y} / \mathrm{N}$

Some factors identified did not have equivalent data in the IDS-TILDA study e.g. vitamin D, calcium.

*Factors with low prevalence rates $<5 \%$ are not included in overall analysis

\subsection{Data Analysis}

For the purposes of this paper the statistical package for social science (SPSS) v24 was used. Preliminary analysis was carried out which included frequencies, distribution and identification of missing values. With regards missing values only valid percentages are presented. A $p$-value of 0.05 was considered statistically significant. Bivariate correlation for QUS categories was calculated with Pearson's coefficient of correlation. Overall relationship between the dependent variable QUS identified poor bone health and the statistically significant risk factors are presented. The measures of effect of the factors studied on the dependent variable were adjusted for age and expressed by the Odds Ratio (OR) and calculated by simple models of multinomial logistic regression. The level of significance was $5 \%$ and Confidence Intervals $(\mathrm{Cl})$ of $95 \%$ were calculated. 


\subsection{Ethics Statement}

Full ethical approval was granted for this study by the Faculty of Health Sciences Ethics Committee and by the ethical committees established by the services providers included in the study. All participants provided informed consent or were supported to do so. To enable this all information was presented in accessible easy read formats and participant family or guardians were also invited to support consent where necessary [45].

\section{Results}

\subsection{Demographic Profile}

In total 244 men participated in this study aged 43 years and above, with the majority within the $50-64$ year age category $(48.8 \%, n=119)$. Most had a moderate level of intellectual disability $(46.3 \%$, $\mathrm{n}=101)$ and lived predominantly in supported accommodation. Very few had a doctor's diagnosis of osteoporosis $(6 \%, n=15)$, however on objective measurement over $70 \%$ ( $n=173$ ) were within the osteopenic $(34.8 \%, n=85)$ and osteoporotic $(36.1 \%, n=88)$ categories respectively and yet just $18 \%(n=38)$ men had had a DXA scan. Just under half were within the severe dependence category on the Barthel's Index $(45.2 \%, n=145)$. Full description of the study sample characteristics can be viewed in table 2.

Table 2 Demographic profile and bone health status $(N=244)$.

\begin{tabular}{|c|c|c|c|}
\hline Characteristic & & $n$ & $\%$ \\
\hline \multirow[t]{3}{*}{ Age } & $43-49$ & 80 & 32.8 \\
\hline & $50-64$ & 119 & 48.8 \\
\hline & $65+$ & 45 & 18.4 \\
\hline \multirow[t]{3}{*}{ Level of ID* } & Mild & 45 & 20.6 \\
\hline & Moderate & 101 & 46.3 \\
\hline & Severe/Profound & 72 & 33.0 \\
\hline \multicolumn{4}{|l|}{ Living Circumstance** } \\
\hline & Indep/Family & 36 & 15.0 \\
\hline & Community Group Home & 106 & 44.2 \\
\hline & Residential Setting & 98 & 40.8 \\
\hline \multirow[t]{2}{*}{ Aetiology of ID } & Down Syndrome & 44 & 18.0 \\
\hline & ID of other aetiology & 200 & 82.0 \\
\hline Doctor's diagnosed osteoporosis & & 15 & 6.0 \\
\hline $\begin{array}{l}\text { Attended bone screening in the last } 2 \text { years } \\
\text { (DXA) }\end{array}$ & & 38 & 18.0 \\
\hline \multirow[t]{3}{*}{ QUS OM bone health } & Normal & 71 & 29.1 \\
\hline & Osteopenia & 85 & 34.8 \\
\hline & Osteoporosis & 88 & 36.1 \\
\hline \multirow[t]{3}{*}{ Barthel's Index } & Independent & 48 & 20.2 \\
\hline & Slight dependence & 41 & 17.2 \\
\hline & Moderate Dependence & 43 & 18.1 \\
\hline
\end{tabular}


*Missing obs: 26 men could not verify their level of ID

**Missing obs: 4 men did not confirm living circumstance

On comparing those who had a diagnosis and those who did not it can be seen in table 3 that 9 in 10 men with a non-normal QUS score, i.e. they fell within the osteopenic and osteoporotic ranges, did not have a doctor's diagnosis.

Table 3 Diagnosed and undiagnosed cases of osteoporosis and osteopenia.

\begin{tabular}{|c|c|c|c|c|c|c|c|}
\hline \multirow{3}{*}{$\begin{array}{l}\text { QUS objective } \\
\text { measurement * }\end{array}$} & \multicolumn{6}{|c|}{ Doctor's diagnosis of osteoporosis** } & \multirow{3}{*}{$\begin{array}{l}\text { Number in } \\
\text { sample }\end{array}$} \\
\hline & \multicolumn{3}{|c|}{ Undiagnosed Cases } & \multicolumn{3}{|c|}{ Diagnosed Cases } & \\
\hline & $\mathrm{n}$ & $\%$ & $95 \% \mathrm{Cl}$ & $\mathrm{n}$ & $\%$ & $95 \% \mathrm{Cl}$ & \\
\hline Normal & 66 & 95.5 & $87.5-98.4$ & 3 & 4.5 & $1.6-12.5$ & 69 \\
\hline Osteopenia & 80 & 95.2 & $83.1-95.3$ & 4 & 4.8 & $1.8-11.0$ & 84 \\
\hline Osteoporosis & 80 & 90.8 & 88.4-98.1 & 8 & 9.1 & 4.9-17.7 & 88 \\
\hline Total & 223 & 93.7 & 89.9-96.1 & 15 & 6.3 & $3.9-10.1$ & 238 \\
\hline
\end{tabular}

*Indicative of risk of the presence of osteoporosis and osteopenia measurement as measured by QUS

**Missing obs: A number of men did not answer the question on doctor's diagnosis

$\mathrm{Cl}=$ confidence interval

\subsection{Presence of Modifiable and Non-Modifiable Risk Factors for Poor Bone Health}

On examination of the risk factors both modifiable and non-modifiable risk factors are very evident with antiepileptic medicines $(36.7 \% n=123)$, having epilepsy $(28.8 \% n=72)$ and difficulty walking $(25.9 \% n=64)$ being among the highest non modifiable factors noted (see figure 2 for all non-modifiable risk factors). 


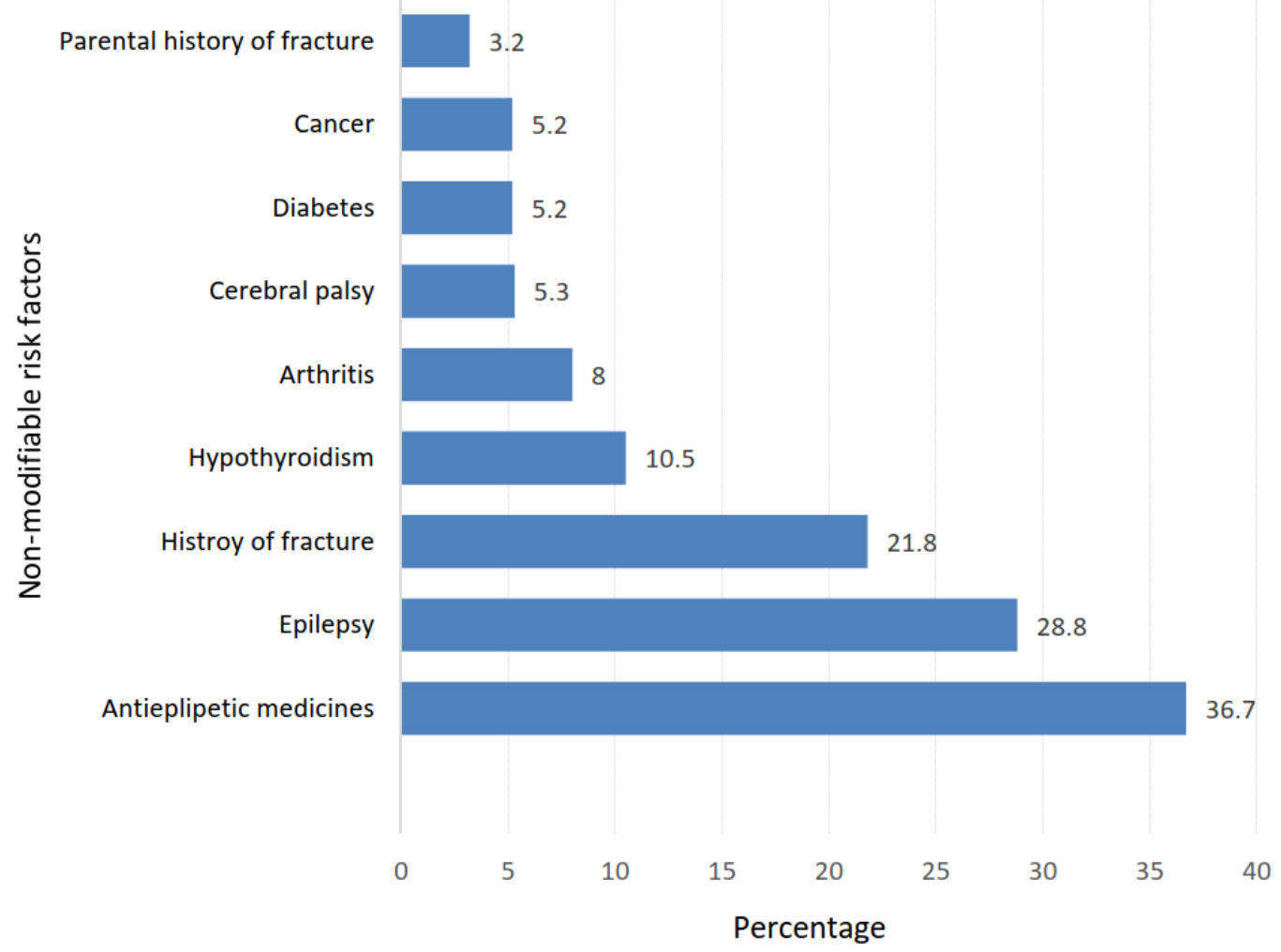

Figure 2 Non-modifiable risk factors for poor bone health.

Among the modifiable factors, low grip strength $(98.0 \%, n=197 / 247)$, low activity levels (69.6\% $n=172 / 247)$ and chronic constipation $(35.6 \% n=88 / 247)$ were the top three risk factors identified, (see figure 3) for all modifiable factors.

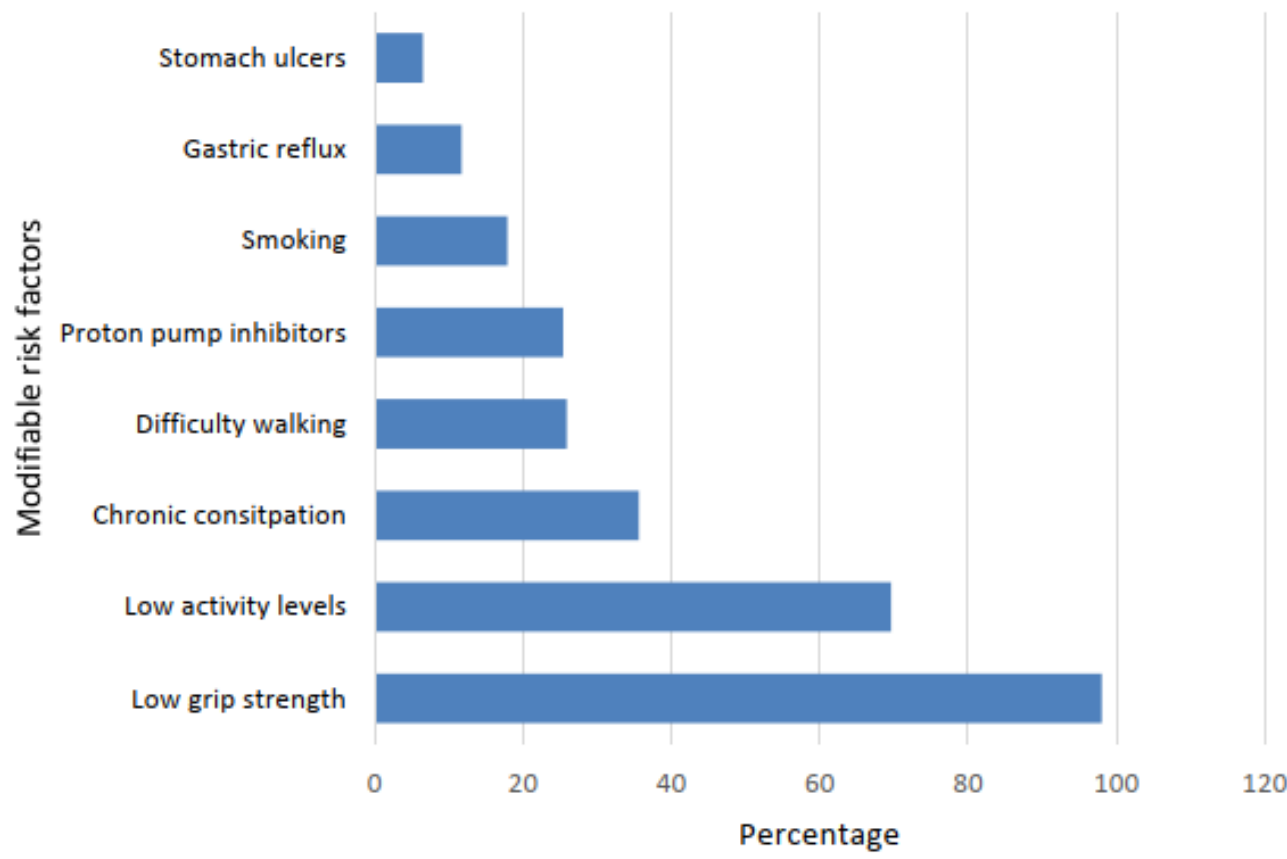

Figure 3 Modifiable risk factors for poor bone health. 


\subsection{Relationship between Modifiable and Nonmodifiable Risk Factor, and Objectively Measured Bone Health}

It can be seen in table 4 a number of the risk factors demonstrated statistically significant relationship with objectively measured bone health. Those with a more severe to profound level of intellectual disability $(p=0.001)$, those living in residential $(p<0.0001)$ with difficulty walking $(p<0.0001)$ and having greater dependence measured on the Barthel's index $(p<0.0001)$ have a significant relationship with poor bone health. Interestingly both medicines examined are significant with proton pump inhibitors highly significant $(p<0.0001)$.

Table 4 Relationship between modifiable and non-modifiable risk factors and QUS objectively measured bone health.

\begin{tabular}{|c|c|c|c|c|c|c|}
\hline \multirow[t]{3}{*}{ Risk Factor } & \multicolumn{3}{|c|}{ QUS t-score } & \multirow[t]{3}{*}{$x^{2}$} & \multirow[t]{3}{*}{$d f$} & \multirow[t]{3}{*}{ p-value* } \\
\hline & Normal & Osteopenia & Osteoporosis & & & \\
\hline & $n(\%)$ & $n(\%)$ & $n(\%)$ & & & \\
\hline Age & & & & 6.411 & 4 & 0.171 \\
\hline $43-49$ & $28(35.0)$ & $31(38.6)$ & $21(26.3)$ & & & \\
\hline $50-64$ & $31(26.1)$ & $42(35.3)$ & $46(38.7)$ & & & \\
\hline $65+$ & $12(26.7)$ & $12(26.7)$ & $21(46.7)$ & & & \\
\hline Level of ID & & & & 19.131 & 4 & 0.001 \\
\hline Mild & $18(40.0)$ & $17(37.8)$ & $10(22.2)$ & & & \\
\hline Moderate & $32(31.7)$ & $38(37.6)$ & $31(30.7)$ & & & \\
\hline Severe/Profound & $10(13.9)$ & $22(30.6)$ & $40(55.6)$ & & & \\
\hline Living Circumstance & & & & 25.656 & 4 & $<0.0001$ \\
\hline Family/Indep. & $21(58.3)$ & $9(25.0)$ & $6(16.7)$ & & & \\
\hline $\mathrm{CGH}$ & $32(30.2)$ & $38(35.8)$ & $36(34.0)$ & & & \\
\hline Residential & $15(15.3)$ & $37(37.8)$ & $46(46.9)$ & & & \\
\hline ID Aetiology & & & & 17.404 & 2 & $<0.0001$ \\
\hline Down Syndrome & $23(52.3)$ & $15(34.0)$ & $6(13.6)$ & & & \\
\hline ID other & $48(24.0)$ & $70(35.0)$ & $82(41.0)$ & & & \\
\hline Has Epilepsy & & & & 7.908 & 2 & 0.019 \\
\hline
\end{tabular}




$\begin{array}{llll}\text { Yes } & 11(15.7) & 30(42.9) & 29(41.4) \\ \text { No } & 57(33.5) & 54(31.8) & 59(34.7)\end{array}$

Difficulty Walking

$34.420 \quad 2<0.0001$

No difficulty

$63(36.2) \quad 65(37.4) \quad 46(26.4)$

Difficulty

$4(6.3) \quad 18(28.6) \quad 41(65.1)$

History of Fracture

$\begin{array}{lll}11.903 & 2 & 0.003\end{array}$

Yes

$10(19.6) \quad 12(23.5) \quad 29(34.1)$

No

$56(30.6) \quad 71(38.8) \quad 56(30.6)$

Chronic Constipation

$\begin{array}{lll}12.838 & 2 & 0.002\end{array}$

Yes

$15(17.9) \quad 26(31.0) \quad 43(51.2)$

No

$51(33.3) \quad 58(37.9) \quad 44(28.8)$

Gastric Reflux

Disease

$\begin{array}{lll}5.891 & 2 & 0.053\end{array}$

Yes

$9(33.3) \quad 4(14.8) \quad 14(51.9)$

No

$57(27.1) \quad 80(38.1) \quad 73(34.8)$

Grip Strength

$\begin{array}{lll}3.399 & 2 & 0.183\end{array}$

$<30$ Kgs

$65(33.9) \quad 70(36.5) \quad 57(29.7)$

$>30 \mathrm{kgs}$

$3(75.0) \quad 0(0.0)$

$1(25.0)$

Physical Activity Level

$\begin{array}{lll}11.805 & 4 & 0.19\end{array}$

$\begin{array}{llll}\text { Low } & 37(22.4) & 65(39.4) & 63(38.2) \\ \text { Moderate } & 25(39.1) & 17(26.6) & 22(34.4) \\ \text { High } & 5(62.5) & 1(12.5) & 2(25.0)\end{array}$

Barthel's Index

$55.622 \quad 6 \quad<0.0001$

Independent

$24(50.0) \quad 16(33.3) \quad 8(16.7)$

Slight Dependence

$23(56.1) \quad 12(29.3) \quad 6(14.6)$

Moderate

Dependence

$9(20.9) \quad 20(46.5) \quad 14(32.6)$ 


\begin{tabular}{|c|c|c|c|c|c|c|}
\hline Severe Dependence & $11(10.4)$ & $36(34.0)$ & $59(55.7)$ & & & \\
\hline Medications AEDs & & & & 9.199 & 2 & 0.010 \\
\hline Yes & 18 (18.9) & $34(35.8)$ & $43(45.3)$ & & & \\
\hline No & $53(35.6)$ & $51(34.2)$ & $45(30.2)$ & & & \\
\hline Medications PPI & & & & 16.116 & 2 & $<0.0001$ \\
\hline Yes & $11(18.0)$ & $15(24.6)$ & $35(57.4)$ & & & \\
\hline No & $60(32.8)$ & $70(38.3)$ & $53(29.0)$ & & & \\
\hline
\end{tabular}

Reporting results that did not violate the assumptions as all expected cell size $>5$

Alpha set at 0.05

\subsection{Multinomial Logistic Regression of QUS Measured Osteopenia and Osteoporosis}

The multinominal logistic regression model contains 6 significant independent variables (moderate and severe dependence on the Barthels index, difficulty with mobility, the presence of epilepsy and AEDs, the presence of constipation and taking proton pump inhibitors (PPI)). The results demonstrate consistency across a number of factors discriminating osteopenia and osteoporosis from normal bone health. Statistically significant factors to emerge as influencing the presence of osteopenia include those with moderate (AOR 3.708, $\mathrm{Cl} 1.32-10.40, p=0.031$ ) or severe dependence on the Barthels Index (AOR 5.33, $\mathrm{Cl} 2.07-13.71, p=0.001$ ) and those with epilepsy being almost 3 times more likely to present with osteopenia (AOR 2.844, Cl 1.295-6.247, $p=0.009$ ). With regard osteoporosis a similar picture emerges relating to moderate and severe dependence on the Barthels Index with those scoring within these categories being 5 to 16 times more likely to present with osteoporosis (AOR 5.463, Cl 1.66-17.97, $p=0.005$, AOR 16.786, Cl 5.858-48.1, $p<0.0001$ ). Those with mobility difficulty were 13 times more likely to present with osteoporosis (AOR 13.71, $\mathrm{Cl}$ 4.55-41.201, $p<0.0001)$, those presenting with chronic constipation had a 3-fold increased risk (AOR3.378, $\mathrm{Cl} 1.633-6.987, p<0.0001$ ). Those on AEDs were over twice as likely to present with osteoporosis (AOR 2.780, $\mathrm{Cl}$ 1.56-7.44, $p=0.003$ ) and finally those on PPIs were over three times more likely to present with osteoporosis (AOR 3.41, $\mathrm{Cl} 1.56-7.44, p=0.002$ ). The remaining predictors can be observed in table 5 . To note some of the confidence intervals were very wide indicating that there is a need for further investigation and possibly the sample size was too small. 
Table 5 Multinomial logistic regression of the risk factors for QUS t-score measured osteopenia and osteoporosis in men ( $N=335)$.

\begin{tabular}{|c|c|c|c|c|c|c|c|}
\hline \multicolumn{2}{|l|}{ Risk Factor } & \multicolumn{3}{|c|}{ Osteopenia } & \multicolumn{3}{|c|}{ Osteoporosis } \\
\hline & & $\begin{array}{l}\text { P- } \\
\text { Value }\end{array}$ & AOR* & Cl 95\% & P-Value & AOR & $\mathrm{Cl} 95 \%$ \\
\hline \multirow[t]{3}{*}{$\begin{array}{l}\text { Barthels } \\
\text { Indep.) }\end{array}$} & $\begin{array}{l}\text { Slight } \\
\text { dependence }\end{array}$ & 0.747 & 0.854 & $\begin{array}{l}0.327- \\
2.228\end{array}$ & 0.0 .735 & 0.809 & $\begin{array}{l}0.237- \\
2.76\end{array}$ \\
\hline & $\begin{array}{l}\text { Mod } \\
\text { dependence }\end{array}$ & 0.013 & 3.708 & $\begin{array}{l}1.321- \\
10.407\end{array}$ & 0.005 & 5.463 & $\begin{array}{l}1.661- \\
17.973\end{array}$ \\
\hline & $\begin{array}{l}\text { Severe } \\
\text { dependence }\end{array}$ & 0.001 & 5.336 & $\begin{array}{l}2.077- \\
13.710\end{array}$ & 0.0001 & 16.786 & $\begin{array}{l}5.858- \\
48.100\end{array}$ \\
\hline $\begin{array}{l}\text { Mobility } \quad \text { (ref } \quad \text { No } \\
\text { difficulty) }\end{array}$ & Difficulty & 0.10 & 4.469 & $\begin{array}{l}1.427- \\
13.992\end{array}$ & 0.0001 & 13.716 & $\begin{array}{l}4.566- \\
41.201\end{array}$ \\
\hline Epilepsy (ref No epilepsy) & & 0.009 & 2.844 & $\begin{array}{l}1.295- \\
6.247\end{array}$ & 0.23 & 2.508 & $\begin{array}{l}1.138- \\
5.526\end{array}$ \\
\hline $\begin{array}{l}\text { Constipation (ref No } \\
\text { constipation) }\end{array}$ & & 0.218 & 1.599 & $\begin{array}{l}0.757- \\
3.378\end{array}$ & 0.001 & 3.378 & $\begin{array}{l}1.633- \\
6.987\end{array}$ \\
\hline $\begin{array}{l}\text { Gastric Reflux (ref No } \\
\text { reflux) }\end{array}$ & & 0.067 & 0.317 & $\begin{array}{l}0.092- \\
1.087\end{array}$ & 0.839 & 1.100 & $\begin{array}{l}0.439- \\
2.760\end{array}$ \\
\hline $\begin{array}{l}\text { AED medications (ref No } \\
\text { AEDs) }\end{array}$ & & 0.055 & 1.966 & $\begin{array}{l}0.987- \\
3.918\end{array}$ & 0.003 & 2.780 & $\begin{array}{l}1.402- \\
5.511\end{array}$ \\
\hline $\begin{array}{l}\text { PPI medications (ref No } \\
\text { PPIs) }\end{array}$ & & 0.706 & 1.179 & $\begin{array}{l}0.501- \\
2.773\end{array}$ & 0.002 & 3.414 & $\begin{array}{l}1.566- \\
7.442\end{array}$ \\
\hline
\end{tabular}

*Adjusted Odds Ratio

\section{Discussion}

Osteoporosis is an insidious condition that is frequently associated with women [32] however it is evident in this study that men with an intellectual disability and their carers need to be cognisant of and pay attention to osteoporosis. The extraordinary gap between the prevalence of doctor's diagnosis versus objectively measured osteoporosis needs attention. A number of risk factors have been identified that contribute to increasing the likelihood of men presenting with undiagnosed cases of osteoporosis and osteopenia. Key risk factors are evident however what has emerged from this study are factors that may not normally be considered and may be unique to this population however this requires further research.

It is evident that the doctor's diagnosed cases are quite low in this study at just $6 \%(n=15)$ and when the objectively measured cases are compared (34.8\% osteopenia, $36.1 \%$ osteoporosis) there is reason to assume an undiagnosed proportion of men with intellectual disability exists. This high prevalence confirms findings in previous work by Bastiaanse and colleagues [14] who also utilised an Achilles QUS to examine bone health and found $43.7 \%(n=339)$ within the objectively measure osteoporosis category and of this $38.7 \%$ were men. This differs greatly from the osteoporosis prevalence of $16 \%(n=11)$ identified in a study by Vice and colleagues [57] however their study was 
based on BMD identified through a chart review and the sample was relatively small, they had 69 contributing participants who were based solely in a residential facility, and as can be seen from this study attendance for DXA can be low. Although Vice and colleagues found no association with gender, a greater proportion of their study group were men. A similar picture emerged within the general population study TILDA [58] whereby they found that a proportion of men who were objectively measured, had undiagnosed poor bone health, however the figures were substantially different to this study (3\% versus 36\%). With consideration to osteopenia, a state that contributes to risk of fracture, attention needs to be paid and not overlooked. Although there is no statistical significance between the presence of objectively measured poor bone health and age in this study, it is accepted that the presence of osteoporosis increases with age. Examining the age adjusted logistic model a number of factors strongly emerge, namely the Barthel Index categorisation with those identified as being moderately or severely dependent at greater risk for overall poor bone health. Whilst the $\mathrm{Cl}$ are wide, this finding does make clinical sense when you consider the items within this scale would imply greater dependence is possibly indicative of increasing frailty [59]. It is therefore concerning that attention to the bone health of men with intellectual disability does not seem to be garnering sufficient attention. There is a paucity of investigation among men with intellectual disability however within the general population literature it is noted that the diagnosis of osteoporosis can present a challenge to their masculinity because of that predominant female association [32] which may account for this lack of attention. This perception could similarly be the case for men with intellectual disability or it may be the fact that as the focus is not predominantly on men when it comes to this condition, their carers may simply be unaware how at-risk men with intellectual disability are too.

Observing the other demographics in the study, what is emerging is the association with level of intellectual disability and living circumstance. It appears that those with a more severe to profound level of intellectual disability and those living in residential settings are more likely to present with poorer bone health. This is unsurprising when clinically those with more multiple complex health needs generally tend to have more severe or profound intellectual disability and tend to require greater support particularly medical and nursing care [60]. However, another complication arises when communication is considered. Those with more severe to profound intellectual disability also may present with more communication difficulties and barriers, with many unable to express verbally [42]. As osteoporosis is a silent condition, often only diagnosed post first clinical fracture, if individuals are unable to express their experience unreported fracture is a possibility. People with intellectual disability may have difficulty expressing pain and this is particularly concerning when it comes to vertebral fractures, one of the common osteoporotic fractures which is often ignored is back pain maybe something that is put up with. It must be remembered that fracture begets fracture and the need for robust skeletal assessment and management especially post initial fracture can stop the fragility fracture cycle. Considering that over $21 \%$ of men in this study experienced a fracture and less than $18 \%$ had bone screening it is concerning that hidden cases are present particularly when all other risk factors identified in this cohort are taken into consideration. However, it must be noted that the question asked of the participants was 'have you ever had a bone break or fracture' no distinction was made between fragility and traumatic fractures therefore in all likelihood some of these fractures are as a result of trauma. That said, it is imperative that men with intellectual disability and their carers keep bone health screening in mind as part of an overall health assessment. There are no set of guidelines to direct this care, and concern continues to be 
raised in the general population about men's bone health, for example deMartinis and colleagues highlight the gender gap that exists noting that men are not widely represented in osteoporosis research [61]. What is concerning from the intellectual disability field is that this is a cohort who are frequently overlooked and omitted from research and often miss out on health checks [36, 62]. When you consider that osteoporosis research does not get sufficient focus overall coupled with the fact that there are no specific guidelines for individuals with intellectual disability, the disadvantage for men with intellectual disability increases.

Epilepsy is a prevalent issue among those with intellectual disability, which can contribute to falls and in the presence of osteoporosis may result in fracture. However, it is the antiepileptic medications (AED) that are detrimental to bone health particularly long term use as would be the case for many of the men in this study. It can be seen in this study that epilepsy and taking AEDs were statistically significant factors. Many participants in this study were on long term use of AEDs and the challenge is that the adverse effects of AEDs on bone health may stay hidden and take years to clinically manifest. Therefore, negative impact on bone health has most probably already occurred. Coupled with this the fact that many individuals with ID can present with refractory epilepsy there may be a reluctance by their physician to change their current regimen $[63,64]$. In this study there is a significant association between AEDs and poorer bone health. It is essential therefore that the connection between adverse bone health and AEDs is recognised in practice [43, 44]. Another medication that surprisingly was associated with the presence of poor bone health was proton pump inhibitors (PPI). Gastrointestinal conditions are noted as highly prevalent among those with intellectual disability and it can be seen within this study that constipation and gastric reflux have a negative effect on bone health. Constipation, ulcers and gastric reflux are evident however GIT conditions are factors that can be modifiable. These are of course reflective of overall poor gut health which of course will impact on essential vitamin and nutrient absorption leading to overall poor health and ultimately impact on bone health. The associated medications also come with osteoporotic implications. It has been noted that the use of PPI medications among those with intellectual disability is particularly widespread [65]. Arj and colleagues demonstrated the increased use of PPI was positively associated with an increase in risk of developing osteoporosis. Esomeprazole, one type of PPI commonly acquired over the counter, was independently associated with significant reduction in $\operatorname{BMD}[66,67]$. Bahtiri and colleagues recommend consideration be given to BMD screening in the case of prolonged PPI use. Considering that those on PPIs emerged in this study as being over 3 times more likely to present with osteoporosis further consideration of the use of PPIs and overall GIT health among those with ID is warranted. This is an important consideration in light of the fact that no guidelines exist for individuals with intellectual disability, emphasising the need to raise awareness of the link between these medicines and their impact on bone health [68].

Bones are living tissue and require impact exercise to stimulate regeneration, it is evident from this study that the levels of physical activity are below that which would accrue health benefit ultimately having a negative impact on bone health. However, it must also be noted that many of the men had difficulty walking with the majority of these men having indications of osteoporosis $(65 \%, p<0.0001)$ a factor previously noted among individuals with intellectual disability [69]. This difficulty in walking could also explain the high levels of dependence as identified by Barthel's index. Weight bearing and resistance exercise are ideal to promote good bone health however the 
literature is replete with evidence that adults with intellectual disability are less active particularly older adults [70].

\subsection{Limitation}

Whilst the authors endeavoured to be as robust in identifying all risks, small sample size for some factors has excluded them from the final analysis. All doctors' diagnosis are self-reported however time was allowed for medical file access.

\section{Conclusions}

In this study men presented with a high risk for osteoporosis and had a high prevalence of fracture. A number of significant risk factors were identified however the common risks normally associated with osteoporosis were not as evident. The findings provide novel and valuable information to be considered in future interventions aiming to increase awareness of osteoporosis among men with intellectual disability and identifying modifiable factors that can be addressed to improve the current bone health of these individuals. The many campaigns through broadcast media and health promotion undertaken by health authorities are certainly not sufficient to get the message to people with intellectual disability and their carers. Osteoporosis is not a female condition alone. It is time for the spotlight to be on men to ensure they are as aware of their risk of osteoporosis as women. Projections place men on a trajectory of continuous increased risk, poor bone health and consequently the deleterious outcome, that of fracture. Therefore, there is a need for clear guidelines for men with intellectual disability. Osteoporosis is not inevitable and in fact can be reversed by addressing risk factors. It is clear from this study that further research is warranted to explore risk further.

\section{Acknowledgments}

The authors would like to acknowledge and thank the participants of the IDS-TILDA study, their families and carers, the service providers, the advocacy consultation groups and the scientific advisory group for their continued contributions and support.

\section{Authors Contribution}

EB was responsible for data collection, developing the article concept, interpreting the analysis, drafting and editing the article, and final approval. RC was responsible for data analysis and interpretation, critical revision of the article. AD was responsible for drafting the article and critical revisions. MY was responsible for drafting the article and critical revisions. JBW contributed to data interpretation, critical revisions and final approval of the article. PMcC contributed to data interpretation, critical revisions and final approval of the article. MMcC contributed to data interpretation, critical revisions and final approval of the article. 


\section{Funding}

This research was funded by the Health Research Board and the Department of Health in Ireland [HRA-PHS-2012-14]. The funding body did not play a role in the study design or writing of the manuscript.

\section{Competing Interests}

The views expressed are those of the authors and are not necessarily those of the Department of Health, The Health Research Board or Trinity College Dublin. The authors have declared that no competing interests exist.

\section{References}

1. Krahn GL, Hammond L, Turner A. A cascade of disparities: Health and health care access for people with intellectual disabilities. Ment Retard Dev Disabil Res Rev. 2006; 12: 70-82.

2. Kerr M. Improving the general health of people with learning disabilities. Adv Psychiatr Treat. 2004; 10: 200-206.

3. McCarron M, Carroll R, Kelly C, McCallion P. Mortality rates in the general Irish population compared to those with an intellectual disability from 2003 to 2012. J Appl Res Intellect Disabil. 2015; 28: 406-413.

4. Krahn GL, Walker DK, Correa-De-Araujo R. Persons with disabilities as an unrecognized health disparity population. Am J Public Health. 2015; 105: S198-S206.

5. Kanis JA, Melton III LJ, Christiansen C, Johnston CC, Khaltaev N. The diagnosis of osteoporosis. J Bone Miner Res. 1994; 9: 1137-1141.

6. Jasien J, Daimon CM, Maudsley S, Shapiro BK, Martin B. Aging and bone health in individuals with developmental disabilities. Int J Endocrinol. 2012; 2012: e469235.

7. Burke ÉA, Carroll R, O’Dwyer M, Walsh JB, McCallion P, McCarron M. Osteoporosis and people with Down syndrome: A preliminary descriptive examination of the intellectual disability supplement to the Irish longitudinal study on ageing wave 1 results. Health. 2018; 10: 12331249.

8. Choksi P, Jepsen KJ, Clines GA. The challenges of diagnosing osteoporosis and the limitations of currently available tools. Clin Diabetes Endocrinol. 2018; 4: 12.

9. Akkawi I, Zmerly H. Osteoporosis: Current concepts. Joints. 2018; 6: 122-127.

10. Vidal M, Thibodaux RJ, Neira LF, Messina OD. Osteoporosis: A clinical and pharmacological update. Clin Rheumatol. 2019; 38: 385-395.

11. Gold DT, Williams SA, Weiss RJ, Wang Y, Watkins C, Carroll J, et al. Impact of fractures on quality of life in patients with osteoporosis: A US cross-sectional survey. J Drug Assess. 2019; 8: 175183.

12. Whitney DG, Whibley D, Jepsen KJ. The effect of low-trauma fracture on one-year mortality rate among privately insured adults with and without neurodevelopmental disabilities. Bone. 2019; 129: 115060.

13. Baptista F, Varela A, Sardinha LB. Bone mineral mass in males and females with and without Down syndrome. Osteoporos Int. 2005; 16: 380-388. 
14. Bastiaanse LP, Mergler S, Evenhuis HM, Echteld MA. Bone quality in older adults with intellectual disabilities. Res Dev Disabil. 2014; 35: 1927-1933.

15. Burke É, Carroll R, O’Dwyer M, Walsh JB, McCallion P, McCarron M. Quantitative examination of the bone health status of older adults with intellectual and developmental disability in Ireland: A cross-sectional nationwide study. BMJ Open. 2019; 9: e026939.

16. Frighi V, Morovat A, Andrews TM, Rana F, Stephenson MT, White SJ, et al. Vitamin D, bone mineral density and risk of fracture in people with intellectual disabilities. J Intellect Disabil Res. 2019; 63: 357-367.

17. Hilgenkamp TI, van Wijck R, Evenhuis HM. Subgroups associated with lower physical fitness in older adults with ID: Results of the HA-ID study. Res Dev Disabil. 2014; 35: 439-447.

18. Hamzaid NH, O'Connor HT, Flood VM. Observed dietary intake in adults with intellectual disability living in group homes. Nutrients. 2020; 12: 37.

19. Srikanth R, Cassidy G, Joiner C, Teeluckdharry S. Osteoporosis in people with intellectual disabilities: A review and a brief study of risk factors for osteoporosis in a community sample of people with intellectual disabilities. J Intellect Disabil Res. 2011; 55: 53-62.

20. Lin LP, Hsu SW, Yao CH, Lai WJ, Hsu PJ, Wu JL, et al. Risk for osteopenia and osteoporosis in institution-dwelling individuals with intellectual and/or developmental disabilities. Res Dev Disabil. 2015; 36: 108-113.

21. Brown MJ, Mezuk B. Brains, bones, and aging: Psychotropic medications and bone health among older adults. Curr Osteoporos Rep. 2012; 10: 303-311.

22. LaCombe JM, Roper RJ. Skeletal dynamics of Down syndrome: A developing perspective. Bone. 2020; 133: 115215.

23. O'Dwyer M, Peklar J, McCallion P, McCarron M, Henman MC. Factors associated with polypharmacy and excessive polypharmacy in older people with intellectual disability differ from the general population: A cross-sectional observational nationwide study. BMJ Open. 2016; 6: e010505.

24. Katz S, Weinerman S. Osteoporosis and gastrointestinal disease. Gastroenterol Hepatol. 2010; 6: 506-517.

25. Zhao LJ, Liu YJ, Liu PY, Hamilton J, Recker RR, Deng HW. Relationship of obesity with osteoporosis. J Clin Endocrinol Metab. 2007; 92: 1640-1646.

26. Emerson $E$, Hatton $C$. Health inequalities and people with intellectual disabilities. Cambridge: Cambridge University Press; 2013. pp.176.

27. Melville CA, Cooper SA, Morrison J, Allan L, Smiley E, Williamson A. The prevalence and determinants of obesity in adults with intellectual disabilities. J Appl Res Intellect Disabil. 2008; 21: 425-437.

28. Curtis JS, Kennedy SE, Attarha B, Edwards L, Jacob R. Upper gastrointestinal disorders in adult patients with intellectual and developmental disabilities. Cureus. 2021; 13: e15384.

29. Adler RA. Update on osteoporosis in men. Best Pract Res Clin Endocrinol Metab. 2018; 32: 759772.

30. Cawthon PM, Shahnazari M, Orwoll ES, Lane NE. Osteoporosis in men: Findings from the osteoporotic fractures in men study (MrOS). Ther Adv Musculoskelet Dis. 2016; 8: 15-27.

31. Ebeling PR, Cicuttini F, Scott $D$, Jones $G$. Promoting mobility and healthy aging in men: $A$ narrative review. Osteoporos Int. 2019; 30: 1911-1922. 
32. Kanis JA, Johnell O, Odén A, Johansson $H$, McCloskey EF. FRAX ${ }^{\mathrm{TM}}$ and the assessment of fracture probability in men and women from the UK. Osteoporos Int. 2008; 19: 385-397.

33. Solimeo SL. Living with a 'women's disease': Risk appraisal and management among men with osteoporosis. J Mens Health. 2011; 8: 185-191.

34. Compton M, Ben Mortenson W, Sale J, Crossman A, Ashe MC. Men's perceptions of living with osteoporosis: A systematic review of qualitative studies. Int J Orthop Trauma Nurs. 2019; 33: 11-17.

35. Burke E, McCarron M, Carroll R, McGlinchey E, McCallion P. What it's like to grow older: The aging perceptions of people with an intellectual disability in Ireland. Ment Retard. 2014; 52: 205-219.

36. Mayor S. Half of patients with learning disability miss out on annual GP health check. BMJ. 2017; 357: j1773.

37. Ali A, Scior K, Ratti V, Strydom A, King M, Hassiotis A. Discrimination and other barriers to accessing health care: Perspectives of patients with mild and moderate intellectual disability and their carers. PloS ONE. 2013; 8: e70855.

38. Smith MV, Adams D, Carr C, Mengoni SE. Do people with intellectual disabilities understand their prescription medication? A scoping review. J Appl Res Intellect Disabil. 2019; 32: 13751388.

39. Flood B, Henman MC. Experiences of the medication use process by people with intellectual disabilities. What a pharmacist should know! Pharmacy. 2021; 9: 24.

40. Iacono T, Bigby C, Unsworth C, Douglas J, Fitzpatrick P. A systematic review of hospital experiences of people with intellectual disability. BMC Health Serv Res. 2014; 14: 505.

41. Northway R, Dix A. Improving equality of healthcare for people with learning disabilities. Nurs Times. 2019; 115: 27-31.

42. Cartwright L, Reid M, Hammersley R, Walley RM. Barriers to increasing the physical activity of people with intellectual disabilities. Br J Learn Disabil. 2017; 45: 47-55.

43. McCarron M, Swinburne J, Burke E, McGlinchey E, Mulryan N, Andrews V, et al. Growing older with an intellectual disability in Ireland 2011: First results from the Intellectual Disability Supplement to the Irish Longitudinal Study on Ageing (IDS-TILDA) [Internet]. Dublin: School of Nursing and Midwifery, Trinity College Dublin; 2011. Available from: https://www.tcd.ie/tcaid/assets/pdf/idstildareport2011.pdf.

44. Burke, EA, McCallion P, McCarron M. Advancing years, different challenges: Wave 2 IDS-TILDA. Dublin: School of Nursing and Midwifery, Trinity College; 2014. Available from: https://www.tcd.ie/tcaid/assets/pdf/Wave_2_Report_October_2014.pdf.

45. Burke ÉA, Walsh JB, McCallion P, McCarron M. Making reasonable adjustment to enable and support people with intellectual disability engage in objective health measures in a research study-the health fair in the intellectual disability supplement to the Irish longitudinal study on ageing. Inclusion. 2020; 8: 124-137.

46. Kelly F, Kelly C, O'Donohoe A. Annual report of the national intellectual disability database committee 2012. Dublin: Health Research Board (HRB); 2012; HRB Statistics Series 19.

47. Hans D, Hartl F, Krieg MA. Device-specific weighted T-score for two quantitative ultrasounds: Operational propositions for the management of osteoporosis for 65 years and older women in Switzerland. Osteoporos Int. 2003; 14: 251-258. 
48. Krieg MA, Barkmann R, Gonnelli S, Stewart A, Bauer DC, Barquero LD, et al. Quantitative ultrasound in the management of osteoporosis: The 2007 ISCD Official Positions. J Clin Densitom. 2008; 11: 163-187.

49. Hans D, Dargent-Molina P, Schott AM, Sebert JL, Cormier C, Kotzki PO, et al. Ultrasonographic heel measurements to predict hip fracture in elderly women: The EPIDOS prospective study. Lancet. 1996; 348: 511-514.

50. Ansari M. Bone tissue regeneration: Biology, strategies and interface studies. Prog Biomater. 2019; 8: 223-237.

51. International Physical Assessment Questionnaire (IPAQ). Available from: http://www.sdp.univ.fvg.it/sites/default/files/IPAQ English self-admin long.pdf.

52. Cruz-Jentoft AJ, Baeyens JP, Bauer JM, Boirie Y, Cederholm T, Landi F, et al. Sarcopenia: European consensus on definition and diagnosis: Report of the European working group on sarcopenia in older people. Age Ageing. 2010; 39: 412-423.

53. Cruz-Jentoft AJ, Bahat G, Bauer J, Boirie Y, Bruyère O, Cederholm T, et al. Sarcopenia: Revised European consensus on definition and diagnosis. Age Ageing. 2019; 48: 16-31.

54. World Health Organisation. Assessment of fracture risk and its application to post-menopausal osteoporosis. Geneva: World Health Organisation; 1994; WHO technical report series 843.

55. International Osteoporosis Foundation. Education hub [Internet]. Nyon: International Osteoporosis Foundation. Available from: https://www.osteoporosis.foundation/educationalhub\#main.

56. National Institutes of Health (NIH) Osteoporosis and Related Bone Diseases, National Resource Center. Osteoporosis overview [Internet]. Bethesda: National Institutes of Health (NIH) Osteoporosis and Related Bone Diseases, National Resource Center; 2020. Available from: https://www.bones.nih.gov/health-info/bone/osteoporosis/overview.

57. Vice MA, Nahar VK, Ford MA, Bass MA, Johnson AK, Davis AB, et al. Risk factors for low bone mineral density in institutionalized individuals with developmental disabilities. Health Promot Perspect. 2015; 5: 147-152.

58. Barrett A, Burke H, Cronin H, Hickey A, Kamiya Y, Kenny RA, et al. Fifty plus in Ireland 2011: First results from the Irish Longitudinal Study on Ageing (TILDA). Dublin: Royal College of Surgeons in Ireland; 2011.

59. Rockwood K, Mitnitski A. Frailty in relation to the accumulation of deficits. J Gerontol A Biol Sci Med Sci. 2007; 62: 722-727.

60. Collin C, Wade DT, Davies S, Horne V. The Barthel ADL Index: A reliability study. Int Disabil Stud. 1988; 10: 61-63.

61. Shapiro BK, O'Neill ME. Developmental delay and intellectual disability. In: Nelson Textbook of Pediatrics. 21st ed. Philadelphia: Elsevier; 2020. pp.283-293.

62. De Martinis M, Sirufo MM, Polsinelli M, Placidi G, Di Silvestre D, Ginaldi L. Gender differences in osteoporosis: A single-center observational study. World J Mens Health. 2021; 39: 750-759.

63. Fridhandler JD, Coelho FM, Tai P, Jette N, Andrade DM. A comparison of antiepileptic drug therapy in patients with severe intellectual disability and patients with normal intellect. Epilepsy Behav. 2012; 25: 196-199.

64. Doran Z, Shankar R, Keezer MR, Dale C, McLean B, Kerr MP, et al. Managing anti-epileptic drug treatment in adult patients with intellectual disability: A serious conundrum. Eur J Neurol. 2016; 23: $1152-1157$. 
65. Walmsley J. Involving users with learning difficulties in health improvement: Lessons from inclusive learning disability research. Nurs Inq. 2004; 11: 54-64.

66. AlMutairi H, O'Dwyer M, McCarron M, McCallion P, Henman MC. The use of proton pump inhibitors among older adults with intellectual disability: A cross sectional observational study. Saudi Pharm J. 2018; 26: 1012-1021.

67. Arj A, Razavi Zade M, Yavari M, Akbari H, Zamani B, Asemi Z. Proton pump inhibitors use and change in bone mineral density. Int J Rheum Dis. 2016; 19: 864-868.

68. Bahtiri E, Islami H, Hoxha R, Qorraj-Bytyqi H, Rexhepi S, Hoti K, et al. Esomeprazole use is independently associated with significant reduction of BMD: 1-year prospective comparative safety study of four proton pump inhibitors. J Bone Miner Metab. 2016; 34: 571-579.

69. Burke EA, McCallion P, Carroll R, Walsh JB, McCarron M. An exploration of the bone health of older adults with an intellectual disability in Ireland. J Intellect Disabil Res. 2017; 61: 99-114.

70. Oviedo GR, Travier N, Guerra-Balic M. Sedentary and physical activity patterns in adults with intellectual disability. Int J Environ Res Public Health. 2017; 14: 1027.

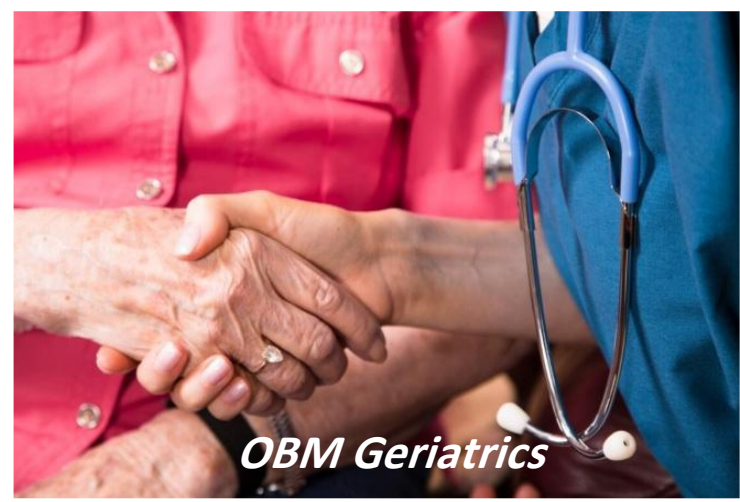

Enjoy OBM Geriatrics by:

1. Submitting a manuscript

2. Joining in volunteer reviewer bank

3. Joining Editorial Board

4. Guest editing a special issue

For more details, please visit: http://www.lidsen.com/journals/geriatrics 